\title{
Nitroxide spin-relaxation over the entire motional range
}

\author{
Marco Bonora, Soraya Pornsuwan, and Sunil Saxena*
}

Department of Chemistry, University of Pittsburgh, Pittsburgh, PA, 15260.

\section{Supporting Information}

Phase Cycle. The general phase cycle for the COSY experiment is shown in Table 1S.

\begin{tabular}{|c|c|c|c|c|c|}
\hline$\varphi_{1}$ & $\varphi_{2}$ & $\mathbf{A}_{1}$ & $\mathbf{B}_{1}$ & $\mathbf{A}_{2}$ & $\mathbf{B}_{2}$ \\
\hline$+\mathrm{x}$ & $+\mathrm{x}$ & $+\mathrm{a}$ & $+\mathrm{b}$ & 0 & 0 \\
\hline$-\mathrm{x}$ & $+\mathrm{x}$ & $-\mathrm{a}$ & $-\mathrm{b}$ & 0 & 0 \\
\hline$+\mathrm{y}$ & $+\mathrm{x}$ & 0 & 0 & $-\mathrm{a}$ & $-\mathrm{b}$ \\
\hline$-\mathrm{y}$ & $+\mathrm{x}$ & 0 & 0 & $+\mathrm{a}$ & $+\mathrm{b}$ \\
\hline
\end{tabular}

Table 1S.

where $\varphi_{1}$ and $\varphi_{2}$ are the phases of the first and second pulses, respectively, and $A_{1}, B_{1}, A_{2}$, and $B_{2}$ are the memory addresses. The first two steps provide the real component in $t_{1}$ and the second two provide the imaginary component in $t_{1}$. This basic four-step phase cycle then gives the full

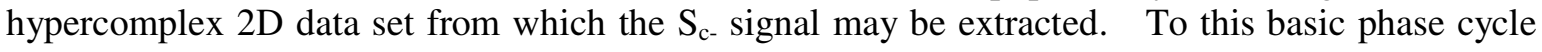
the four-step CYCLOPS sequence is added, making it a 16 step phase cycle. For each step of the phase cycle the signal is averaged and then the phases of the pulses changed for the next step of the phase cycle. By implementing CYCLOPS as shown in Table $2 \mathrm{~S}$ fast temporal cancellation of some of the dead-time artifacts can be achieved.

\begin{tabular}{|c|c|c|c|c|c|}
\hline$\varphi_{1}$ & $\varphi_{2}$ & $\mathbf{A}_{\mathbf{1}}$ & $\mathbf{B}_{\mathbf{1}}$ & $\mathbf{A}_{\mathbf{2}}$ & $\mathbf{B}_{\mathbf{2}}$ \\
\hline$+\mathrm{x}$ & $+\mathrm{x}$ & $+\mathrm{a}$ & $+\mathrm{b}$ & 0 & 0 \\
\hline$-\mathrm{x}$ & $+\mathrm{x}$ & $-\mathrm{a}$ & $-\mathrm{b}$ & 0 & 0 \\
\hline$+\mathrm{y}$ & $+\mathrm{y}$ & $+\mathrm{b}$ & $-\mathrm{a}$ & 0 & 0 \\
\hline$-\mathrm{y}$ & $+\mathrm{y}$ & $-\mathrm{b}$ & $+\mathrm{a}$ & 0 & 0 \\
\hline$-\mathrm{x}$ & $-\mathrm{x}$ & $-\mathrm{a}$ & $-\mathrm{b}$ & 0 & 0 \\
\hline$+\mathrm{x}$ & $-\mathrm{x}$ & $+\mathrm{a}$ & $+\mathrm{b}$ & 0 & 0 \\
\hline$-\mathrm{y}$ & $-\mathrm{y}$ & $-\mathrm{b}$ & $+\mathrm{a}$ & 0 & 0 \\
\hline$+\mathrm{y}$ & $-\mathrm{y}$ & $+\mathrm{b}$ & $-\mathrm{a}$ & 0 & 0 \\
\hline$+\mathrm{y}$ & $+\mathrm{x}$ & 0 & 0 & $-\mathrm{a}$ & $-\mathrm{b}$ \\
\hline$-\mathrm{y}$ & $+\mathrm{x}$ & 0 & 0 & $+\mathrm{a}$ & $+\mathrm{b}$ \\
\hline$-\mathrm{x}$ & $+\mathrm{y}$ & 0 & 0 & $-\mathrm{b}$ & $+\mathrm{a}$ \\
\hline$+\mathrm{x}$ & $+\mathrm{y}$ & 0 & 0 & $+\mathrm{b}$ & $-\mathrm{a}$ \\
\hline$-\mathrm{y}$ & $-\mathrm{x}$ & 0 & 0 & $+\mathrm{a}$ & $+\mathrm{b}$ \\
\hline$+\mathrm{y}$ & $-\mathrm{x}$ & 0 & 0 & $-\mathrm{a}$ & $-\mathrm{b}$ \\
\hline$+\mathrm{x}$ & $-\mathrm{y}$ & 0 & 0 & $+\mathrm{b}$ & $-\mathrm{a}$ \\
\hline$-\mathrm{x}$ & $-\mathrm{y}$ & 0 & 0 & $-\mathrm{b}$ & $+\mathrm{a}$ \\
\hline
\end{tabular}


Table 2S.

Sensitivity to dynamics: The inverse homogeneous linewidth $\left(\mathrm{T}_{\mathrm{m}}\right)$ obtained using SECSY-ESR and the inverse inhomogeneous linewidth obtained using CW-ESR are shown in figure 1S.

(a)

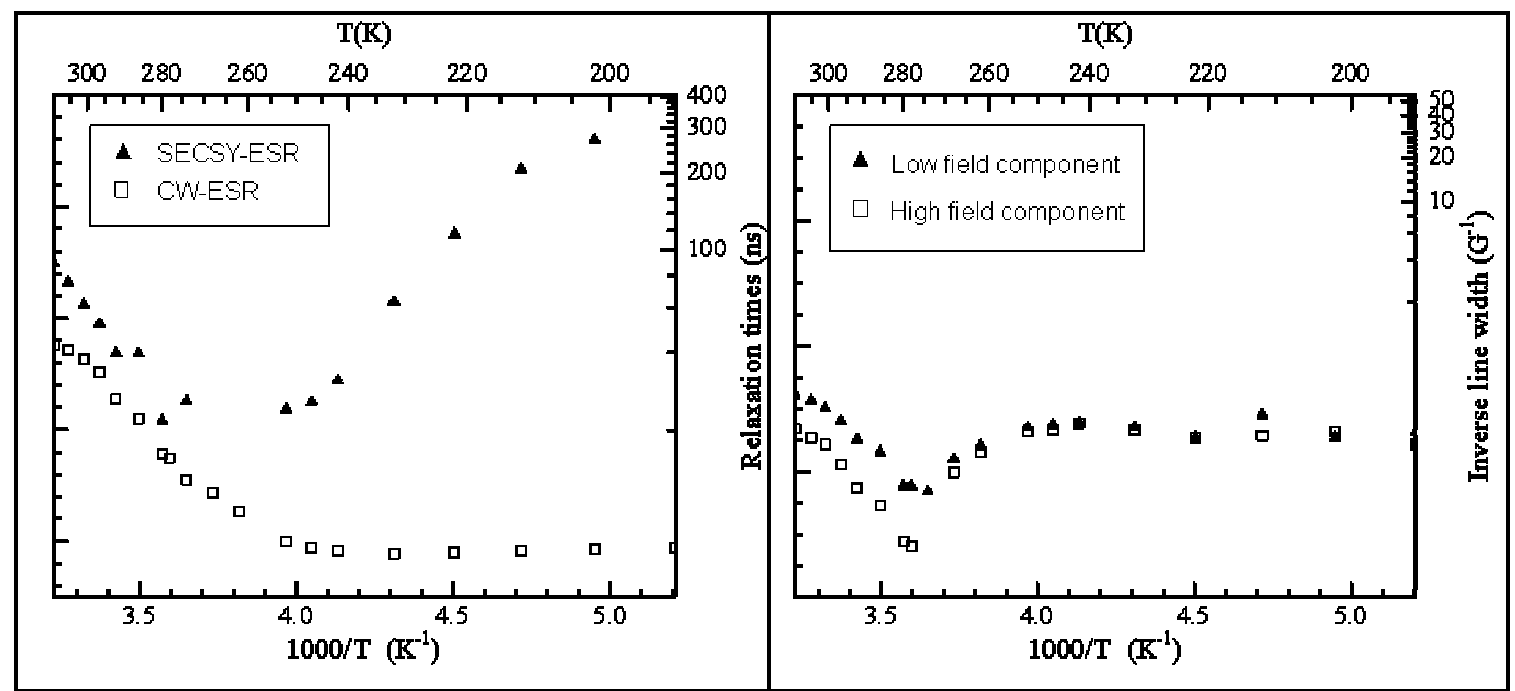

Fig. 1S. (a) The values of $\mathrm{T}_{\mathrm{m}}$ (triangles) and $\mathrm{T}_{\mathrm{m}}{ }^{*}$ (open squares) for the central component and (b) Inverse linewidths for the low-field (triangles) and high-field (open squares) components are reported in function of $1 / \mathrm{T}$ between $310 \mathrm{~K}$ and $192 \mathrm{~K}$. The sensitivity of $\mathrm{T}_{\mathrm{m}} *$ to dynamics practically stops at $\sim 240 \mathrm{~K}$ while $\mathrm{T}_{\mathrm{m}}$ between 240 and $192 \mathrm{~K}$ changes from 32 to $373 \mathrm{~ns}$.

The homogeneous linewidths, $\mathrm{T}_{\mathrm{m}}$, were obtained for the central transitions using procedures described in the text. The CW-ESR data was analyzed as follows. The peak-to-peak linewidth of the central component was determined at all temperatures. The reported $\mathrm{T}_{\mathrm{m}}{ }^{*}$ values were then calculated as:

$T_{m}=\frac{1}{\sqrt{3} \pi \Delta}$, where $\Delta$ is the peak-to-peak linewidth in $\mathrm{MHz}$.

For the other two components the peak-to-peak linewidth was extracted from the CW-ESR spectra in the fast motional regime where lorentzian shapes are expected. In the slow motional regime the lineshapes for these components are complex. In this regime the peak-to-peak linewidth of the derivative of the CW-ESR spectra was determined. These are shown in Fig $1 \mathrm{~S}(\mathrm{~b})$.

The $\mathrm{T}_{\mathrm{m}}$ 's from SECSY-ESR are very sensitive to slow motions $\left(\sim 10^{-4} \mathrm{~s}<\tau_{\mathrm{R}}<5 \times 10^{-8} \mathrm{~s}\right)$ (Figure 1Sa). In CW-ESR the central linewidths show a weaker temperature-dependence but dynamics may be followed until a temperature of $240 \mathrm{~K}$ by obtaining the difference between he central linewidth and the other two (cf. Figures $1 \mathrm{Sa}$ and $1 \mathrm{Sb}$ ). Below $240 \mathrm{~K}$ the linewidths of the all components are also practically independent of temperature. On the other had the $\mathrm{T}_{\mathrm{m}}$ of the central component from SECSY-ESR changes from 32 to $373 \mathrm{~ns}$ for the temperature range of $240-190 \mathrm{~K}$. 